\title{
Over-the-scope clip used to treat duodenal ulcer can cause damage to ulcer base and massive bleeding
}

The efficacy of the over-the-scope clip (OTSC; Ovesco, Tübingen, Germany) to achieve primary hemostasis and prevent rebleeding has been demonstrated in the treatment of gastroduodenal ulcers [1]. Recent data have shown technical success and hemostasis rates of almost $100 \%$ [1-3]. We present the case of technical failure of an OTSC used for a rebleeding duodenal ulcer, leading to massive bleeding when the clip was released ( $\vee$ Video 1 ).

A 61-year-old man was admitted for hematemesis, anemia, and hypotension. A Forrest Ilb ulcer located on the posterior wall of the duodenal bulb was treated by adrenaline and hot biopsy coagulation. He was readmitted a week later for a severe recurrence with hemorrhagic shock. Second gastroscopy confirmed rebleeding from the initial duodenal ulcer graded Forrest Ila, and hemostasis was achieved with hot biopsy forceps coagulation ( $\mathbf{F i g} \mathbf{1} \mathbf{1} \mathbf{a}, \mathbf{b})$. We decided to prevent a new recurrence by applying an OTSC. Unfortunately, release of the OTSC damaged the ulcer base leading to a large defect on the arterial branch and resulting in acute hemorrhagic shock ( Fig.1c,d, $>$ Fig.2a). Endoscopic hemostasis appeared impossible and we transferred the patient as an emergency to the radiology unit.

A computed tomography (CT) scan confirmed a large arterial blush of $8 \mathrm{~mm}$ in diameter ( $\mathbf{F i g} \mathbf{2} \mathbf{2}$, c). Arterial embolization of the gastroduodenal and pancreaticoduodenal arterial ramifications was performed successfully ( $\mathbf{F i g . 2} \mathbf{d}$ ). Five days later, the patient suffered from melena with hemodynamic instability. CT scan concluded rebleeding from the gastroduodenal artery that had undergone embolization. Fortunately, a successful surgical treatment was finally performed, which controlled the bleeding.

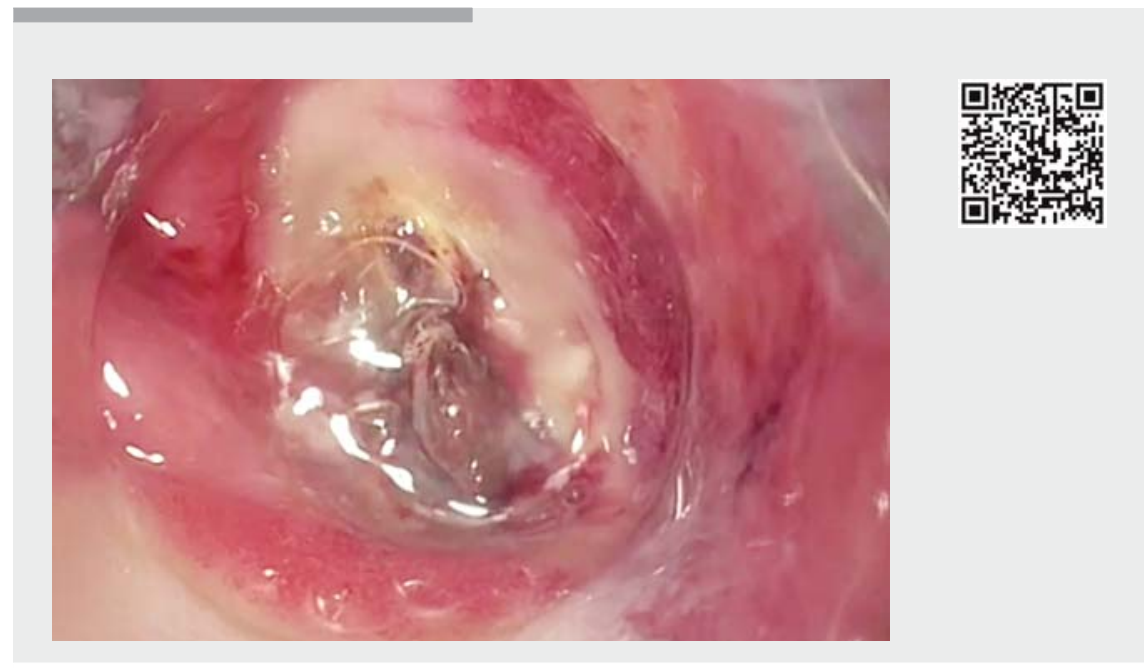

Video 1 The over-the-scope clip damaged the duodenal ulcer base, resulting in massive bleeding from the artery branch.
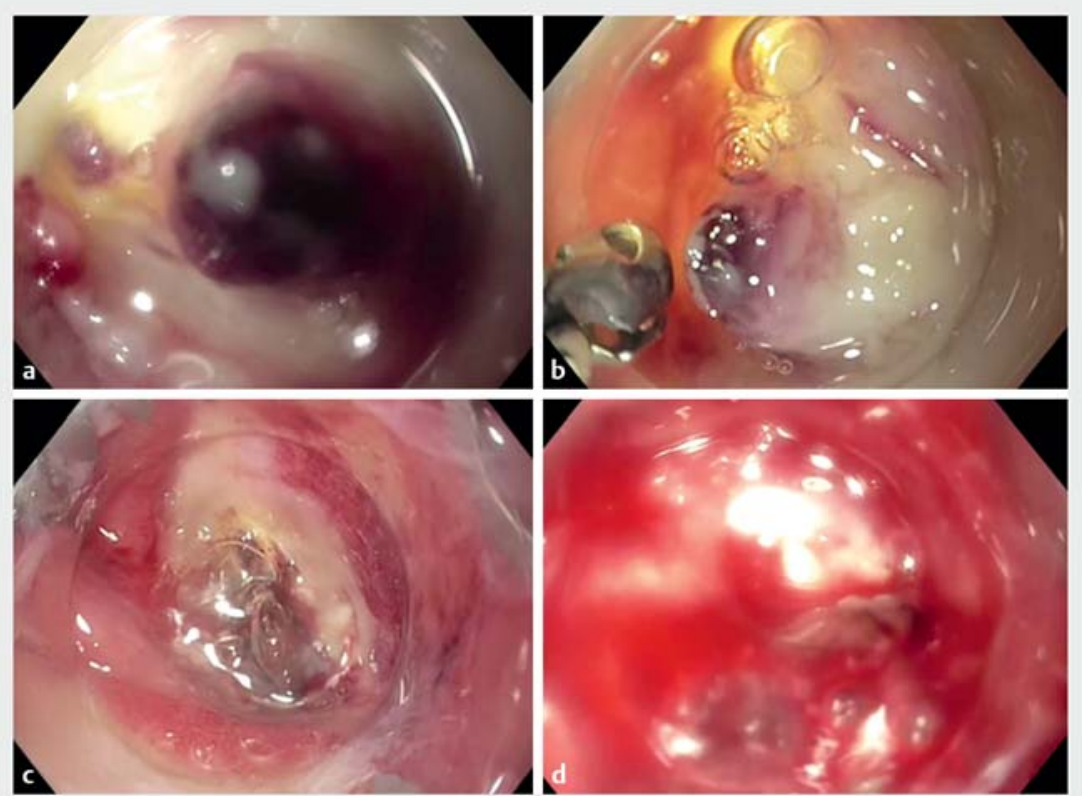

- Fig. 1 Endoscopic management of the duodenal ulcer. a Initial aspect with visible vessel (Forrest Ila), then rapid bleeding with arterial pulse (Forrest la). b Initial hemostasis was achieved with hot biopsy forceps coagulation. c Placement of the over-the-scope clip (OTSC; Ovesco, Tübingen, Germany) to prevent recurrence. $\mathbf{d}$ Release of the OTSC led to massive acute bleeding. 

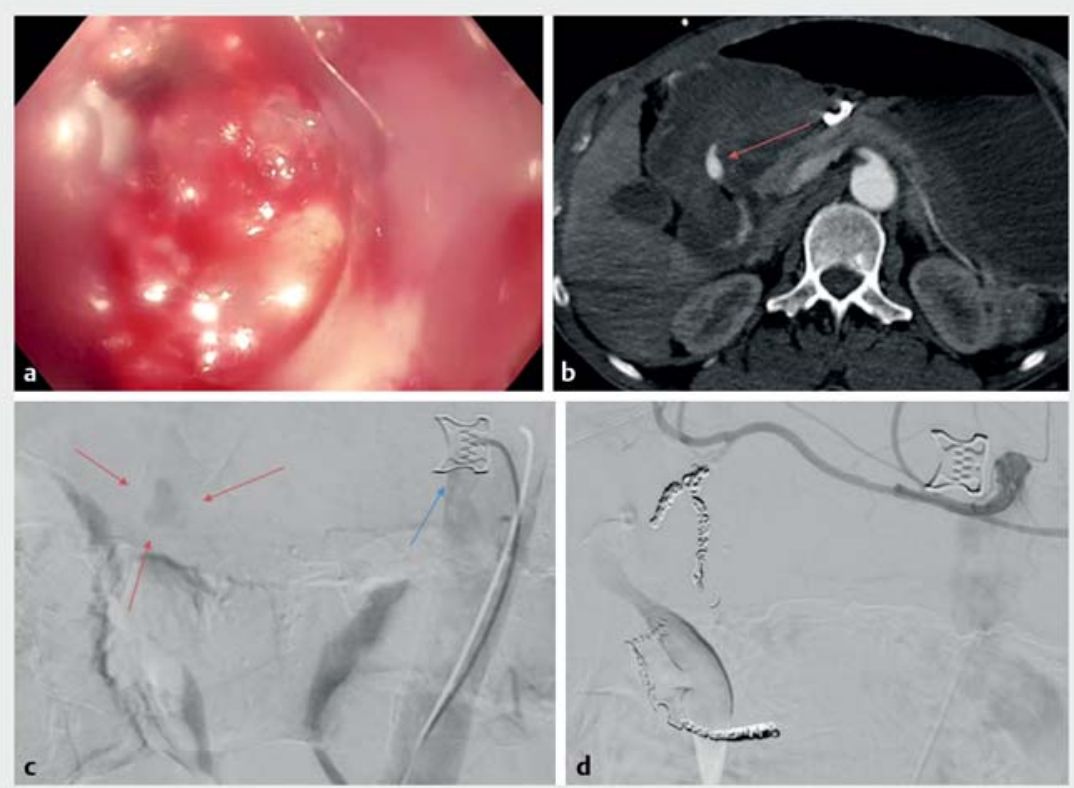

- Fig. 2 Emergency radiologic management. a The massive bleed despite the over-thescope clip (OTSC; Ovesco, Tübingen, Germany) being in place. b Computed tomography scan with contrast showing an 8-mm blush (red arrows) on the gastroduodenal artery and migration of the OTSC clip (blue arrow). c An arteriography was performed and confirmed the massive blush. $\mathbf{d}$ Embolization of the two main feeding vessels was performed.

This case highlights the fact that OTSCs may sometimes dramatically worsen bleeding by ripping out the base of an ulcer and the bleeding vessel. Release of the OTSC may be more challenging in posterior wall and fibrous duodenal ulcers, as previously published [2]. Rescue OTSC placement should be performed in units equipped with interventional radiologists with experience in embolization for cases of massive bleeding.

Endoscopy_UCTN_Code_TTT_1AO_2AD

Competing interests
The authors

Emilien Daire ${ }^{1}$, Emmanuel Forte ${ }^{1}$, Badis Mennassel $^{2}$, Charles-Eric Ber ${ }^{3}$, Emilie Roy ${ }^{4}$, Jérémie Jacques ${ }^{5}$, Mathieu Pioche ${ }^{1}$

1 Department of Endoscopy and Gastroenterology, Pavillon L, Edouard Herriot Hospital, Lyon, France

2 Radiology Unit, Pavillon B, Edouard Herriot Hospital, Lyon, France

3 Anesthesiology Department, Pavillon L, Edouard Herriot Hospital, Lyon, France

4 Digestive Surgery Department, Edouard Herriot Hospital, Lyon, France

5 Department of Endoscopy and Gastroenterology, Dupuytren University Hospital, Limoges, France
Corresponding author

\section{Mathieu Pioche, MD}

Endoscopy unit - Digestive Disease department, Pavillon L - Edouard Herriot Hospital, 69437 Lyon Cedex, France Fax: +33-4-72110147

mathieu.pioche@chu-lyon.fr

\section{References}

[1] Wedi E, Fischer A, Hochberger J et al. Multicenter evaluation of first-line endoscopic treatment with the OTSC in acute non-variceal upper gastrointestinal bleeding and comparison with the Rockall cohort: the FLETRock study. Surg Endosc 2018; 32: 307-314

[2] Manta R, Mangiafico S, Zullo A et al. Firstline endoscopic treatment with over-thescope clips in patients with either upper or lower gastrointestinal bleeding: a multicenter study. Endosc Int Open 2018; 6: E1317E1321

[3] Richter-Schrag H-J, Glatz T, Walker C et al. First-line endoscopic treatment with overthe-scope clips significantly improves the primary failure and rebleeding rates in highrisk gastrointestinal bleeding: a single-center experience with 100 cases. World J Gastroenterol 2016; 22: $9162-9171$

\section{Bibliography}

DOI https://doi.org/10.1055/a-0885-9786

Published online: 2.5.2019

Endoscopy 2019; 51: E213-E214

(c) Georg Thieme Verlag KG

Stuttgart · New York

ISSN 0013-726X

\section{ENDOSCOPY E-VIDEOS \\ https://eref.thieme.de/e-videos}

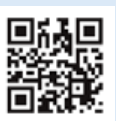

Endoscopy E-Videos is a free access online section, reporting on interesting cases and new

techniques in gastroenterological endoscopy. All papers include a high quality video and all contributions are freely accessible online.

This section has its own submission website at

https://mc.manuscriptcentral.com/e-videos 